\title{
An analysis of the electricity consumption reduction potential of electric motors in the South Korean manufacturing sector
}

\author{
Joon Han • Sun-Jin Yun
}

Received: 2 September 2014 / Accepted: 10 February 2015 /Published online: 27 February 2015

(C) The Author(s) 2015. This article is published with open access at Springerlink.com

\begin{abstract}
Electric motors account for $42.9 \%$ (as of 2010) of electricity consumption in the Korean manufacturing sector, which represents $20.9 \%$ of total electric power demand in Korea. Efficient use of motors in the manufacturing sector is therefore essential in controlling electric power demand in Korea. This study analyzes the potential and economic feasibility of reducing electric motor electricity consumption in the Korean manufacturing sector. Presently, Korea only enforces minimum energy performance standards (MEPS) for three-phase induction electric motors rated $200 \mathrm{~kW}$ or less, and the industrial electricity price is much lower than the Organization for Economic Co-operation and Development (OECD) average. In addition, load factors of electric motors are generally far below optimal efficiency, and variable-speed drive (VSD) installation rates are lower than in other advanced countries. This study analyzes the amount and cost of reducing electricity consumption under each of the following scenarios, modeled as additional strategies to the current MEPS, for reducing energy consumption: (1) expansion of MEPS enforcement, (2) increasing the industrial electricity price, (3) enhancement of motor load factors, and (4) installation of VSDs. This study found that
\end{abstract}

J. Han

Green Technology Center Korea, Seoul, Republic of Korea e-mail: jooniehan@gmail.com

S.-J. Yun $(\bowtie)$

Graduate School of Environmental Studies, Seoul National University, Seoul, Republic of Korea

e-mail: ecodemo@snu.ac.kr increasing the industrial electricity price has the largest electricity reduction potential and is economically most beneficial to the society.

Keywords Electric motor - Energy efficiency. Electricity consumption reduction potential

\section{Introduction}

While South Korea (hereafter Korea) was ranked 15 th in the world in terms of gross domestic product (GDP) in 2011, it was ranked eighth in terms of total electricity consumption, at $455 \mathrm{TWh}$ in the same year. Its electricity intensity was $0.489 \mathrm{kWh} / \mathrm{US} \$ 2005$, ranking the country fifth in the world in 2011. The annual growth rate in electricity demand level during the period of 1973-2010 was $10.1 \%$, the highest among the Organization for Economic Co-operation and Development (OECD) member countries (IEA 2012a). The annual growth rate in electricity demand during the recent decade, 2002-2011, was $6.0 \%$, which was much higher than the annual growth rate of final energy demand over the same period, $2.7 \%$ (MKE and KEEI 2012). Thus, Korea's electricity consumption has been rapidly increasing on an absolute scale and in terms of growth rates.

Thus far, Korea has used supply-side managementoriented energy strategies to meet the rapidly increasing electricity demand. Currently, there are 23 nuclear reactors under operation and five more under construction. Six more reactors will be added by 2024 . Coal-fired and 
LNG-fired power plants with a total capacity of 15.3 GW will also be added by 2027 (MKE 2013). A supply-oriented energy policy was also adopted in the case of renewable energy. The Korean government switched its renewable energy distribution policy instrument from a feed-in-tariff (FIT) to a renewable portfolio standard (RPS) in 2012 in order to supply energy from renewables within a short time period.

Nevertheless, the electricity supply has become more unstable in Korea. Korean society experienced largescale rolling blackouts in 2011, and its electric power reserve rate nosedived to $3.8 \%$ in 2012 from $17.1 \%$ in 2003. Although the government has updated its projections of future electricity demands every 2 years and has increased its power capacity, actual electricity consumption has frequently exceeded estimates by $10 \%$. Meeting exponentially increasing electricity demand will be extremely challenging even with continued increases in the electricity supply.

Considering this aspect, supply-side management alone is not enough. Demand-side management is also important to cope with the rapidly increasing electricity demand. In other words, it is necessary to offset electricity demand increases by means of improved load management and/or through improvements in energy efficiency. Specifically, energy efficiency improvements are important because they can reduce energy use without compromising energy services. They are also beneficial because they contribute to job creation, reductions in energy-related public expenditures, increased energy security, reductions in greenhouse gas (GHG) emissions, energy price moderation, and better natural resource management at the international level (IEA 2012b). In addition, they can be implemented quickly compared to other measures such as regulations and are generally more costeffective. The International Energy Agency (IEA) (2012c) forecasts that the ratio of fuel cost savings to the energy efficiency investment cost will be about 1.9 in OECD and 1.3 in non-OECD countries between 2012 and 2035.

Meanwhile, electric motors are electricity-intensive and consume about one fifth of all electricity in Korea (MKE 2012a). The efficient use of electric motors is critical. As a result, the Korean government introduced the minimum energy performance standard (MEPS) for electric motors in 2008, and existing low-efficiency motors have gradually been replaced with highefficiency motors which meet these criteria. However, as electric motors consume a large amount of electricity, it is necessary to review additional options to reduce electricity consumption and analyze their potential. For example, raising the current low electricity tariffs could reduce the high growth in electricity demand. In addition, increasing load factors and installing variablespeed drives (VSD) can enhance the efficiency of electric motors and generate savings.

Thus, this study develops five alternative scenarios that explore different means of reducing electricity consumption in addition to MEPS and analyzes the electricity reduction potential and economic feasibility of each scenario. As various technologies compete with each other in the electric motor market for cost-effectiveness, this study uses the Model for Energy Supply System Alternatives and their General Environmental Impact (MESSAGE), which is an optimization model that determines the most cost-effective technology mix (IAEA 2007).

This paper is organized as follows. In "Electric motors and strategies to reduce the electricity consumption of motors in Korea," we describe MEPS and the major issues related to electricity consumption by electric motors. In "Methodology," we describe the methodology. The scenarios are described in the "Results" and the results are explained in section "Conclusions." Finally, we discuss policy implications in section "Conclusions."

\section{Electric motors and strategies to reduce the electricity consumption of motors in Korea}

\section{Electric motor electricity consumption in Korea}

As shown in Fig. 1, manufacturing accounted for $48.7 \%$ of electricity sales in Korea (MKE and KEEI 2012), the fifth largest proportion among OECD countries (IEA 2012a). Electric motors accounted for $42.9 \%$ of the total electricity demand in the manufacturing sector (MKE 2012a). Therefore, the electricity used in electric motors involving in the manufacturing sector represents as much as $20.9 \%$ of total electricity use in Korea. Considering this, electricity demand-side management strategies pertaining to the efficient use of electric motors in the Korean manufacturing industry are extremely important.

MEPS for electric motors in Korea

The USA, EU, Canada, Australia, Mexico, China, Brazil, Taiwan, and New Zealand have already adopted MEPS. The Korean government started to introduce MEPS in 2008 for three-phase induction motors of 


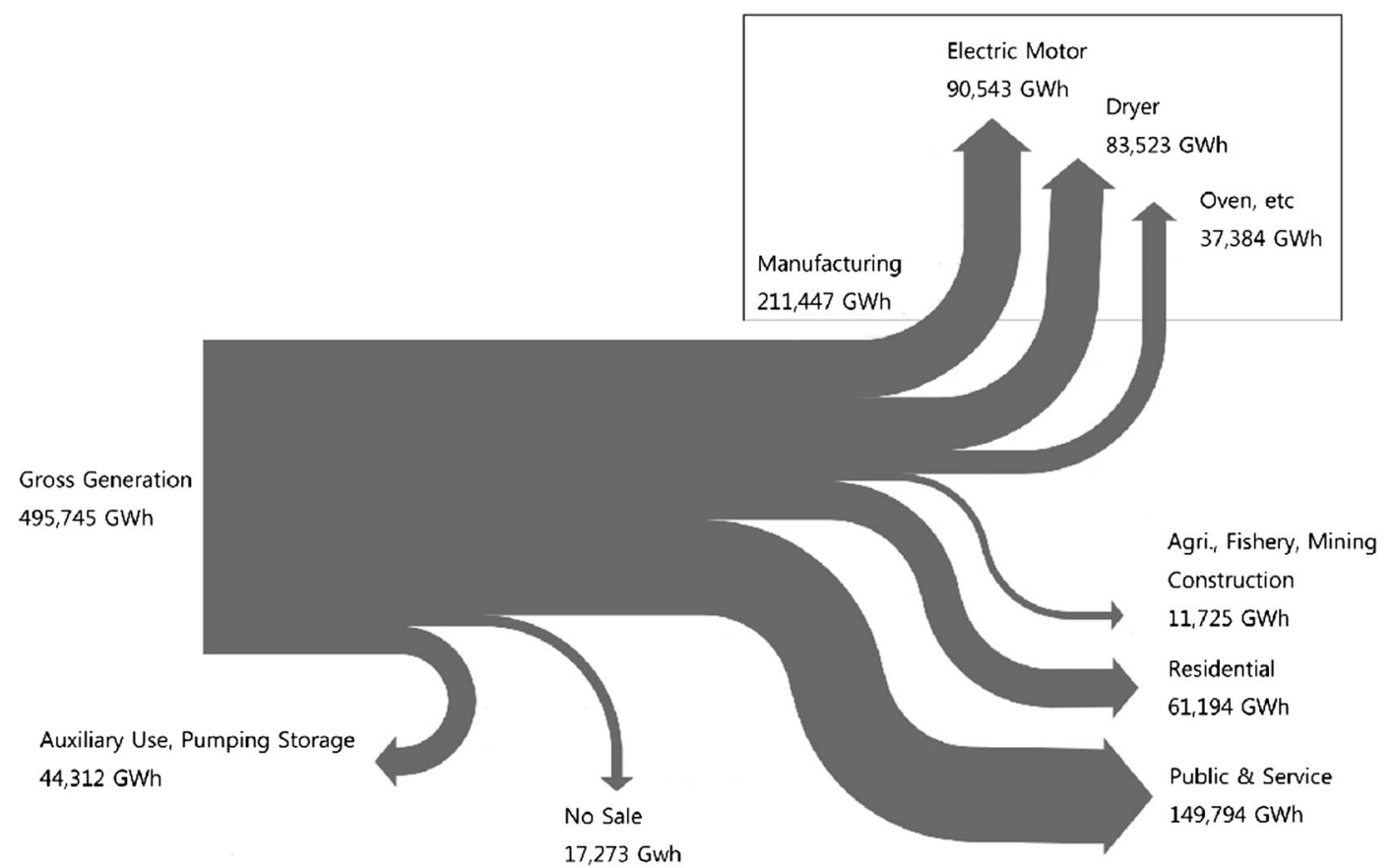

Fig. 1 The amount of electricity in power generation and consumption

$200 \mathrm{~kW}$ or less, a standard which is now mandatory. If electric motors do not comply, their production, import, and sale are prohibited. The efficiency criteria set for three-phase induction motors under MEPS, which is same as IE2 level, are given in Table 1.

Although not currently a compulsory regulation like MEPS, there is also a premium performance standard for three-phase induction motors, which is the same as the IE3 level, as shown in Table 2. This was introduced in April 2012 and will make the production, import, and sale of premium motors (IE3) mandatory from 2015.

Figure 2 shows the IE2 and IE3 level used in Korea, EU, and USA. IE2 means high-efficiency motor and IE3 means premium motor.

Strategies to reduce the electricity consumption of motors

Strategies to reduce the electricity consumption of motors include the application scope of MEPS, the industrial electricity price, and the load factor and installation rate of VSDs.

\section{Application scope of MEPS}

Unlike Korea, the USA and the EU apply MEPS to high-capacity electric motors rated $200 \mathrm{~kW}$ or more.
The Korean government announced that it will expand MEPS to cover motors up to $385 \mathrm{~kW}$ in 2012, but this is yet to be implemented. If this were to be applied and enforced, it would be possible to save more electricity since the electricity consumed at over $200 \mathrm{~kW}$ is estimated to be $9.7-13.4 \%$ of the total consumption of electric motors in Korea.

\section{The industrial electricity price}

The industrial electricity price in Korea is very low compared to those of other advanced countries. When not considering purchasing power parity (PPP), it was the lowest among OECD nations in 2009 (IEA 2013). In addition, the ratio of the electricity price compared to the fossil fuel price is the smallest among OECD countries. Table 3 shows the relative ratio of industrial electricity prices to industrial light oil and natural gas prices in the USA, Japan, Germany, France, Canada, Korea, and the OECD average. Korea has the smallest ratios in the OECD. Also, the ratio of the industrial electricity price compared to the industrial light oil rate in Korea is less than 1. This is known as the "price reversal phenomenon," which intensifies the energy electrification rate, deepens the instability of the electricity supply system, reduces energy efficiency, and increases social conflicts (Seok 2012; Jo 2012). As a result, controlling 
Table 1 MEPS for three-phase induction motors (IE2 level) in Korea (unit: \%)

\begin{tabular}{|c|c|c|c|c|c|c|c|c|}
\hline \multirow[t]{2}{*}{ KW } & \multicolumn{4}{|c|}{ Open type } & \multicolumn{4}{|c|}{ Totally enclosed type } \\
\hline & 2 poles & 4 poles & 6 poles & 8 poles & 2 poles & 4 poles & 6 poles & 8 poles \\
\hline 0.75 & 75.5 & 82.5 & 80.0 & 74.0 & 75.5 & 82.5 & 80.0 & 74.0 \\
\hline 1.5 & 84.0 & 84.0 & 85.5 & 85.5 & 84.0 & 84.0 & 86.5 & 82.5 \\
\hline 2.2 & 84.0 & 86.5 & 86.5 & 86.5 & 85.5 & 87.5 & 87.5 & 84.0 \\
\hline 3.7 & 85.5 & 87.5 & 87.5 & 87.5 & 87.5 & 87.5 & 87.5 & 85.5 \\
\hline 5.5 & 87.5 & 88.5 & 88.5 & 88.5 & 88.5 & 89.5 & 89.5 & 85.5 \\
\hline 7.5 & 88.5 & 89.5 & 90.2 & 89.5 & 89.5 & 89.5 & 89.5 & 88.5 \\
\hline 11 & 89.5 & 91.0 & 90.2 & 89.5 & 90.2 & 91.0 & 90.2 & 88.5 \\
\hline 15 & 90.2 & 91.0 & 91.0 & 90.2 & 90.2 & 91.0 & 90.2 & 89.5 \\
\hline 18.5 & 91.0 & 91.7 & 91.7 & 90.2 & 91.0 & 92.4 & 91.7 & 89.5 \\
\hline 22 & 91.0 & 92.4 & 92.4 & 91.0 & 91.0 & 92.4 & 91.7 & 91.0 \\
\hline 30 & 91.7 & 93.0 & 93.0 & 91.0 & 91.7 & 93.0 & 93.0 & 91.0 \\
\hline 37 & 92.4 & 93.0 & 93.0 & 91.7 & 92.4 & 93.0 & 93.0 & 91.7 \\
\hline 45 & 93.0 & 93.6 & 93.6 & 92.4 & 93.0 & 93.6 & 93.6 & 91.7 \\
\hline 55 & 93.0 & 94.1 & 93.6 & 93.6 & 93.0 & 94.1 & 93.6 & 93.0 \\
\hline 75 & 93.0 & 94.1 & 94.1 & 93.6 & 93.6 & 94.5 & 94.1 & 93.0 \\
\hline 90 & 93.6 & 94.5 & 94.1 & 93.6 & 94.5 & 94.5 & 94.1 & 93.6 \\
\hline 110 & 93.6 & 95.0 & 94.5 & 93.6 & 94.5 & 95.0 & 95.0 & 93.6 \\
\hline 132 & 93.6 & 95.0 & 94.5 & 94.1 & 94.5 & 95.0 & 95.0 & 94.1 \\
\hline 160 & 94.5 & 95.0 & 94.5 & 94.1 & 95.0 & 95.0 & 95.0 & 94.1 \\
\hline 200 & 94.5 & 95.0 & 94.5 & 94.1 & 95.0 & 95.0 & 95.0 & 94.1 \\
\hline
\end{tabular}

These values mean full load nominal efficiency

electricity consumption of electric motors is very difficult with the low electricity price in the manufacturing sector.

\section{Load factor}

The motor load factor refers to the average load compared to the rated capacity of a motor for a given period of time (CEE 2011). The load factor is important with regard to the electricity consumption of a motor as a low load factor can reduce the efficiency of the motor. ${ }^{1}$ Efficiency levels do not differ much at load factors of 75 to $100 \%$, and the efficiency is highest at load factors of 75 to $80 \%$ (CEE 2011). However, the efficiency decreases remarkably at a load factor of $50 \%$ or less

\footnotetext{
${ }^{1}$ In fact, it is whether the average load factor is low or not or whether the load factor varies substantially or not during the course of the motor duty cycle that affects the efficiency of the motor system. However, this paper focuses on the former because oversizing is usually serious and it reduces efficiency.
}

(Beggs 2009), and as the capacity increases, the level for the load factor at which the efficiency decreases rapidly also decreases (Natural Resources Canada 2003).

According to several previous studies and related data, the load factor decreases when the motor capacity is unnecessarily large (Beggs 2009; Bortoni 2009; DOE 2008; Saidur 2010). In the USA, more than $40 \%$ of industrial motors in use were operating at less than a partial load of $40 \%$ (DOE 2002). This resulted from motor oversizing and it showed that matching the size of motor to the load was very important for electricity saving. Therefore, maintaining a high load factor in a motor is necessary to obtain the highest efficiency.

\section{Variable-speed drives}

A VSD is a device that regulates the speed and rotational force or the output torque of mechanical equipment (Saidur et al. 2010). It is an important device when attempting to reduce the electricity consumption of a 
Table 2 Premium performance standard for three-phase motors (IE3 level) in Korea (unit: \%)

\begin{tabular}{|c|c|c|c|c|c|c|c|c|}
\hline \multirow[t]{2}{*}{ KW } & \multicolumn{4}{|c|}{ Open type } & \multicolumn{4}{|c|}{ Totally enclosed type } \\
\hline & 2 poles & 4 poles & 6 poles & 8 poles & 2 poles & 4 poles & 6 poles & 8 poles \\
\hline 0.75 & 77.0 & 85.5 & 82.5 & & 77.0 & 85.5 & 82.5 & 75.5 \\
\hline 1.5 & 85.5 & 86.5 & 87.5 & & 85.5 & 86.5 & 88.5 & 84.0 \\
\hline 2.2 & 85.5 & 89.5 & 88.5 & & 86.5 & 89.5 & 89.5 & 85.5 \\
\hline 3.7 & 86.5 & 89.5 & 89.5 & & 88.5 & 89.5 & 89.5 & 86.5 \\
\hline 5.5 & 88.5 & 91.0 & 90.2 & & 89.5 & 91.7 & 91.0 & 86.5 \\
\hline 7.5 & 89.5 & 91.7 & 91.7 & & 90.2 & 91.7 & 91.0 & 89.5 \\
\hline 11 & 90.2 & 93.0 & 91.7 & & 91.0 & 92.4 & 91.7 & 89.5 \\
\hline 15 & 91.0 & 93.0 & 92.4 & & 91.0 & 93.0 & 91.7 & 90.2 \\
\hline 18.5 & 91.7 & 93.6 & 93.0 & & 91.7 & 93.6 & 93.0 & 90.2 \\
\hline 22 & 91.7 & 94.1 & 93.6 & & 91.7 & 93.6 & 93.0 & 91.7 \\
\hline 30 & 92.4 & 94.1 & 94.1 & & 92.4 & 94.1 & 94.1 & 91.7 \\
\hline 37 & 93.0 & 94.5 & 94.1 & & 93.0 & 94.5 & 94.1 & 92.4 \\
\hline 45 & 93.6 & 95.0 & 94.5 & & 93.6 & 95.0 & 94.5 & 92.4 \\
\hline 55 & 93.6 & 95.0 & 94.5 & & 93.6 & 95.4 & 94.5 & 93.6 \\
\hline 75 & 93.6 & 95.4 & 95.0 & & 94.1 & 95.4 & 95.0 & 93.6 \\
\hline 90 & 94.1 & 95.4 & 95.0 & & 95.0 & 95.4 & 95.0 & 94.1 \\
\hline 110 & 94.1 & 95.8 & 95.4 & & 95.0 & 95.8 & 95.8 & 94.1 \\
\hline 132 & 94.5 & 95.8 & 95.4 & & 95.4 & 95.8 & 95.8 & 94.5 \\
\hline 160 & 95.0 & 95.8 & 95.4 & & 95.4 & 96.2 & 95.8 & 94.5 \\
\hline 200 & 95.0 & 95.8 & 95.4 & & 95.8 & 96.2 & 95.8 & 94.5 \\
\hline
\end{tabular}

motor, as it enables the motor to better match the requirements of the process it is driving. The use of VSDs can reduce the electrical energy required by a motor system by from 5 to $35 \%$ (UNIDO 2010).
Despite the fact that the VSD has a considerable effect on reducing electricity consumption, the percentage of motors installed with VSDs is very low in Korea (1 7\%) (Yun 2009). In fact, the Korean government
Fig. 2 IE2 and IE3 level in Korea, EU, and USA. Note: The values are for totally enclosed type, four-pole motors

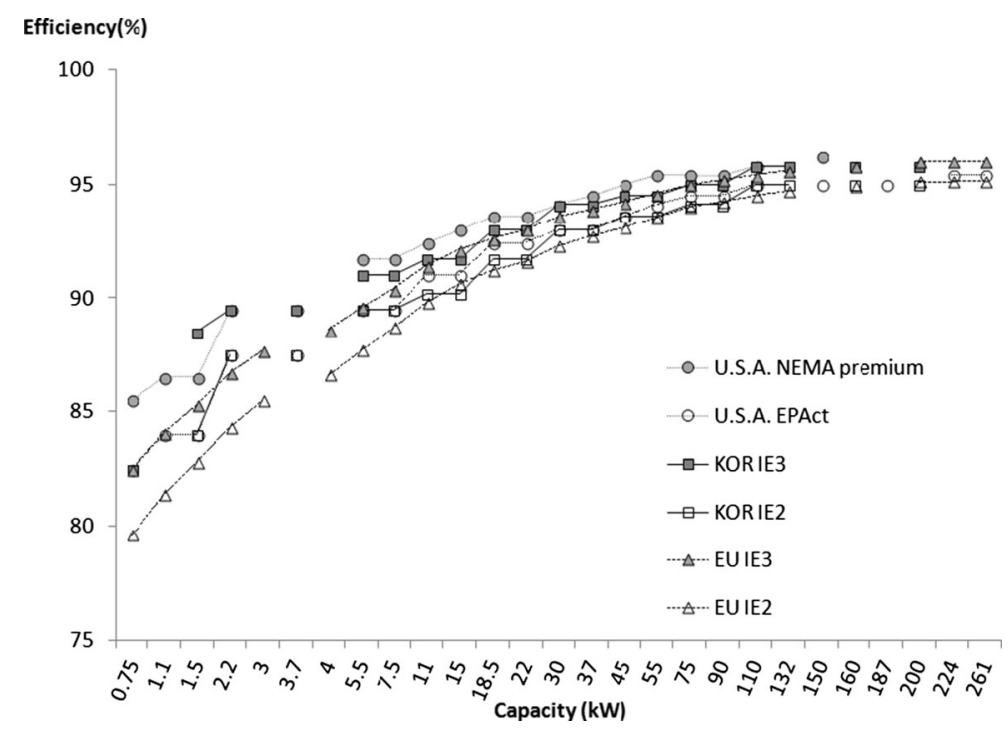


Table 3 The ratio of the industrial electricity price compared to the industrial light oil and natural gas price in major countries

\begin{tabular}{lll}
\hline & $\begin{array}{l}\text { Ratio of industrial } \\
\text { electricity price to } \\
\text { industrial diesel price }\end{array}$ & $\begin{array}{l}\text { Ratio of industrial } \\
\text { electricity price to } \\
\text { industrial natural } \\
\text { gas price }\end{array}$ \\
\hline Japan & 2.50 & 2.92 \\
Germany & 2.35 & 2.63 \\
OECD average & 1.96 & 3.50 \\
France & 1.74 & 2.54 \\
USA & 1.62 & 3.48 \\
Canada & 1.10 & 3.57 \\
South Korea & 0.63 & 1.26 \\
\hline
\end{tabular}

Ratios are calculated from 2008 data of IEA (2013)

started subsidizing high-efficiency VSDs in 2001, but the level of subsidies has differed greatly each year, most recently experiencing a rapid decrease, as shown in Fig. 3.

\section{Methodology}

\section{The MESSAGE model}

In order to analyze the electricity consumption and cost of motors in the manufacturing industry, this study used the MESSAGE model. MESSAGE is a bottom-up model based on detailed data pertaining to technologies as well as an optimization model which determines the most optimal technology mix depending on demand. In the motor market, motors generally compete in terms of cost-effectiveness. MESSAGE can determine an optimal motor technology mix with the lowest cost to meet the electricity demand level. In addition, it can account for various policies and technical situations, such as enforcement of MEPS, load factor improvements, efficiency improvements via VSD installations, and electricity price increases.

The optimization process in the MESSAGE model is based on levelized cost, which is used to compare the unit costs of different technologies over their economic lifetimes. Levelized cost can be calculated by the technology's lifetime, the initial investment cost, operation and maintenance (O\&M) costs, the load factor, and the level of efficiency (Messner and Strubegger 1995).
Major premise and input data

\section{Major preconditions}

The reference year of the analysis is 2010, and the analysis period is from 2010 to 2030 . This study uses a 2005 currency value and a discount rate of $5.0 \%$

\section{Industrial electricity price projection}

The business-as-usual (BAU) scenario reflects the industrial electricity price projection used to forecast the reference electricity demand in the "Sixth Basic Plan for Electricity Demand and Supply" formulated by the Korean government. ${ }^{2}$ It is assumed that the ratio between the OECD average price and the Korean price would remain the same until 2030 in the BAU scenario.

However, the sixth plan was based on the premise that increases in the nominal electricity price would not exceed consumer price index (CPI) inflation (Hur 2013), suggesting future declines in the real rate of electricity. However, this is very unlikely, because the ever increasing growth in electricity demand and ineffective demand-side management is mainly due to the low electricity price in Korea (Jeong 2011; Park 2011; Yun 2013). Accordingly, this study added an electricity price increase scenario, which assumes that the industrial electricity price in Korea would increase by as much as the OECD average until 2030 through a highprice policy. In 2010, the OECD average industrial electricity price (US\$110.8/MWh) was 1.67 times the Korean price (US\$66.3/MWh) (IEA 2013). Therefore, the 2030 OECD average price was assumed to become 159.5 KRW/kWh, 1.67 times the 2030 Korean price (108.0 KRW/kWh). This is illustrated in Fig. 4.

\section{Electricity service projection}

The electricity service demanded by electric motors in the manufacturing sector was estimated based on total industrial electricity demand, the manufacturing sector's proportion of total industrial electricity consumption, and the average efficiency of motors, which is effective

\footnotetext{
${ }^{2}$ It is a plan to present directions for demand-side management targets, an adequate reserve margin, the generation mix, renewables percentage, power plant construction plans, and other related issues based on the electricity demand forecast.
} 


\section{Subsidies} (million KRW)

600,000

(6)

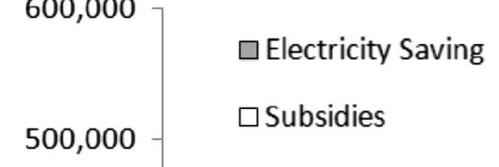

Electricity Saving

(MWh)

30,000

25,000

20,000

15,000

10,000

5,000

100,000

0

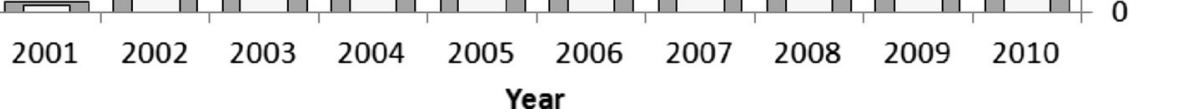

Fig. 3 Trends in subsidies for and electricity savings from high-efficiency VSDs in Korea (2001-2010). Sources: MKE (2012b)

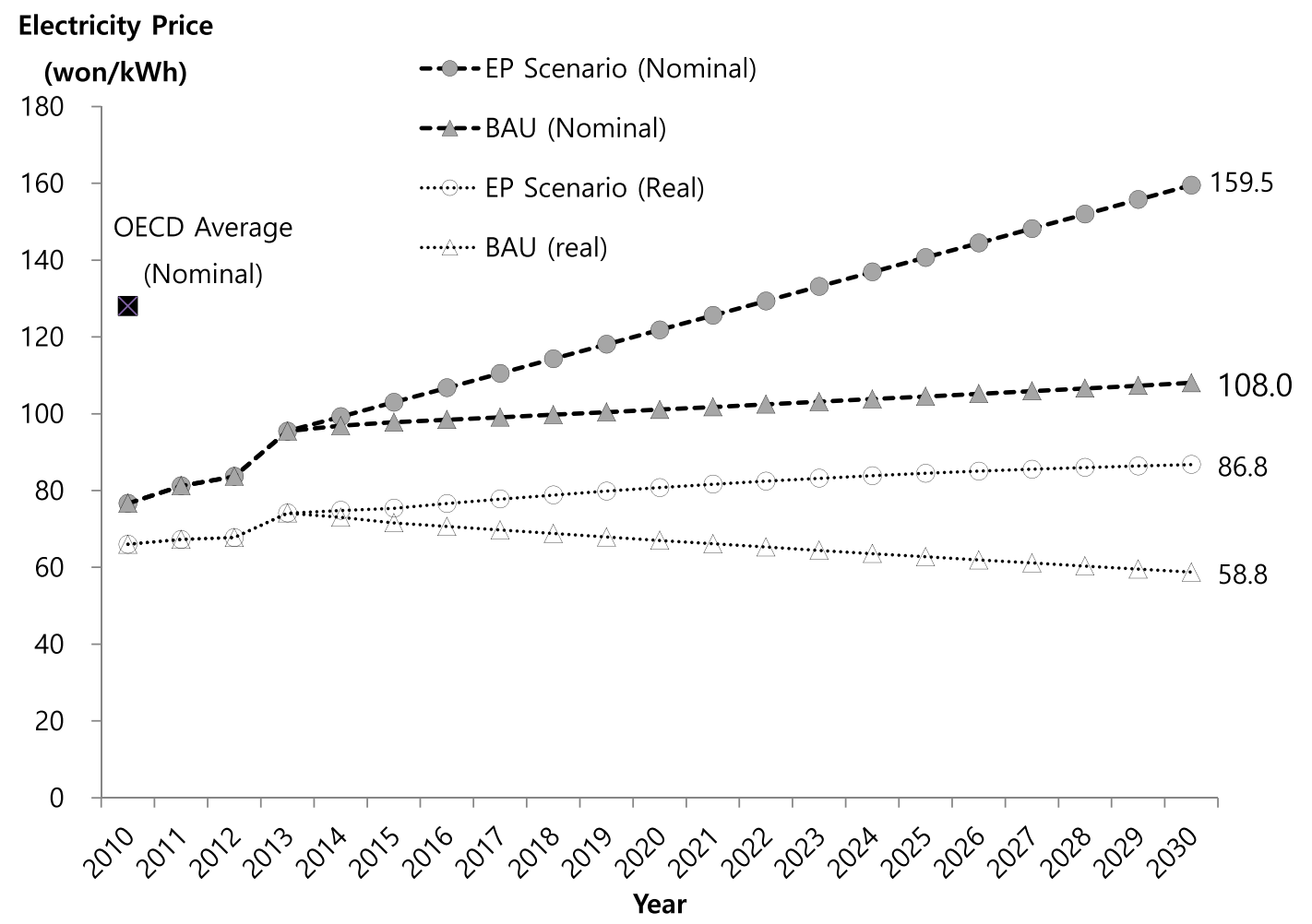

Fig. 4 Industrial electricity price increase scenario 
energy, a proxy variable for energy service (Pachauri and Spreng 2004; Reister and Warren 1981).

The total industrial electricity demand was estimated using Cha et al. (2008)'s industrial electricity demand function, as shown in the equation below. Cha et al.
(2008) derived an electricity demand function through simultaneous equations reflecting the feedback between energy demand and supply and macroeconomic variables. They showed that it is very suitable and stable through a simulation.

$$
\begin{aligned}
& \ln \left(\mathrm{IEle}_{t}\right)=-4.152+0.374 \ln \left(\mathrm{IEle}_{t-1}\right)-0.045 \ln \left(\mathrm{PRIEle}_{t} / \mathrm{CPI}_{t}\right)+0.757 \ln \mathrm{GDP}_{t} \\
& \overline{\sigma^{2}}=0.019, \overline{(0.681)}(0.066) \quad(0.040) \\
& \bar{R}^{2}=0.999, \mathrm{D} . \mathrm{W} .=1.41
\end{aligned}
$$

Values in brackets are the standard errors of estimates.

\section{IEle Industrial electricity (1000 toe) \\ PRIEle Industrial electricity price (1000 KRW/toe) \\ CPI Consumer price index $(2005=100)$ \\ GDP Real GDP (billion KRW, 2000 constant prices)}

Because the price elasticity ${ }^{3}$ of electricity demand varies according to many studies, this study uses data from Kim (2009) and Jeong and Park (2010) in addition to that from Cha et al. (2008). These studies provide the maximum, median, and minimum values for the price elasticity of the electricity demand levels estimated in Korea, respectively. These values are $0.66,0.460$, and 0.045 , respectively.

\section{Historical capacity of motors}

We estimated electric motor supply data for Korean manufacturing by extrapolating raw data from the Korea Energy Management Corporation (KEMCO) (2004) and the Ministry of Knowledge Economy (MKE) (2008). The annual motor supply capacity is shown in Fig. 5.

\section{Electric motor properties}

We used the information from reference KEMCO (2009) for the efficiency, cost (initial investment cost, operation, and maintenance cost), and the new technology introduction time for electric motors. With regard to high-efficiency motors, the average efficiency of threephase induction motors registered as IE2 and IE3 in the

\footnotetext{
${ }^{3}$ Price elasticity of demand is the percentage change in quantity demanded in response to a $1 \%$ change in price.

${ }^{4}$ KEMCO Energy Efficiency Management System homepage http://bpms.kemco.or.kr/efficiency_system/
}

efficiency grading system of $\mathrm{KEMCO}^{4}$ and the average distribution price of high-efficiency motors were used. In addition, the annual motor maintenance cost was assumed to be $10 \%$ of the initial investment cost.

\section{Load factor}

Because the efficiency of an electric motor differs depending on its load factor, it is necessary to adjust the efficiency as input data in the model while considering load factors. Table 4 shows how much different load factors reduce efficiency for motors of different capacities. The values were calculated from the International Motor Selection and Saving Analysis (IMSSA) data ${ }^{5}$ and corroborates Beggs (2009), CEE (2011) or Natural Resources Canada (2003)'s findings that efficiency decreases as the load factor decreases. As the average load factor of Korean industrial electric motors appears to be about $65 \%$ (MKE 2008), the percentage decreases in efficiency for each load factor were also estimated, as shown in Table 4.

\section{VSD}

As shown in Table 5, the United Nations Industrial Development Organization (UNIDO) (2010) data were used to determine the cost of a VSD and its efficiency improvements. The average values were used for the pumping system and the fan, which were the most widely used

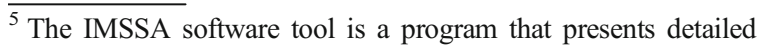
information about motors released onto the market, including information on capacity, enclosure type, number of pole, voltage, efficiency, cost, power factor, torque, and amperage. It is mainly intended for motor suppliers, energy consultants, and motor consumers.
} 


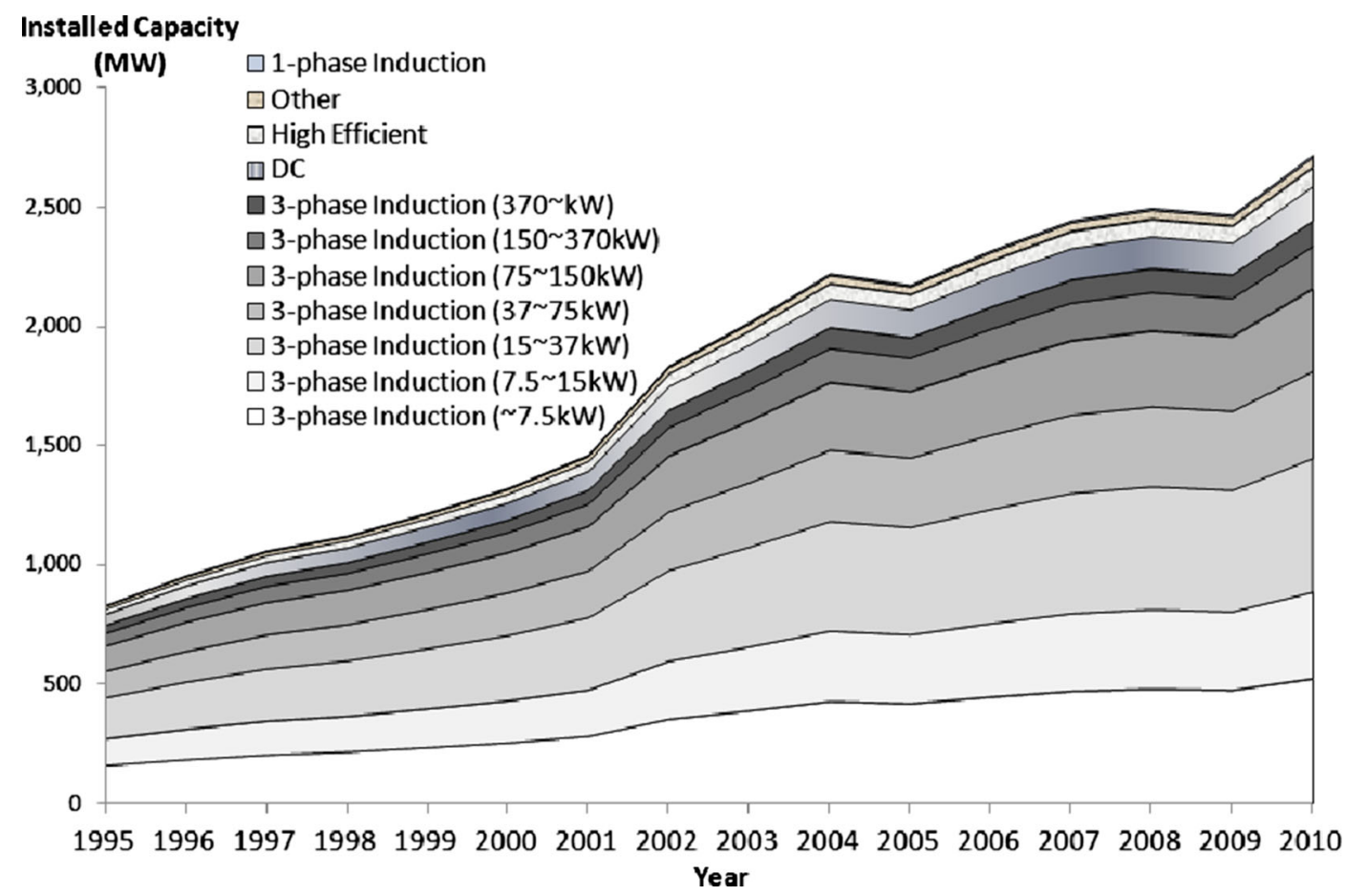

Fig. 5 Estimates of motor supply capacity in Korean manufacturing by year (1995-2010)

types. It was also assumed that an efficiency improvement means a decrease in the input electricity.

\section{Scenarios}

The scenarios for electricity consumption by electric motors in the Korean manufacturing sector are as follows: the BAU scenario represents the current situation, in which MEPS are in effect, and the alternative scenarios represent

Table $4 \%$ Efficiency decreases from maximum efficiency, by capacity and load factor

\begin{tabular}{lllll}
\hline $\begin{array}{l}\text { Capacity } \\
(\mathrm{kW})\end{array}$ & $\begin{array}{l}\text { Load } \\
\text { factor } \\
25 \%\end{array}$ & $\begin{array}{l}\text { Load } \\
\text { factor } \\
50 \%\end{array}$ & $\begin{array}{l}\text { Load } \\
\text { factor } \\
100 \%\end{array}$ & $\begin{array}{l}\text { Load factor } \\
65 \% \\
\text { (estimates) }\end{array}$ \\
\hline$\sim 7.5$ & 14.08 & 2.93 & -0.08 & 2.59 \\
$7.5 \sim 15$ & 7.33 & 1.05 & 0.64 & 1.45 \\
$15 \sim 37$ & 5.48 & 0.81 & 0.56 & 1.12 \\
$37 \sim 75$ & 4.72 & 0.78 & 0.35 & 0.93 \\
$75 \sim 150$ & 4.17 & 0.77 & 0.22 & 0.81 \\
$150 \sim 370$ & 3.17 & 0.79 & 0.09 & 0.64 \\
$370 \sim$ & 2.43 & 0.59 & 0.12 & 0.50 \\
\hline
\end{tabular}

The $65 \%$ data are estimated by the trend of data at 25,50 , and $100 \%$ situations in which additional electricity demand reduction strategies, such as an increase in the industrial electricity price (EP), ${ }^{6}$ an expansion of MEPS (ME), an enhancement of motor load factors (LF), and increased VSD installation (VD) are put into effect. To be more specific, the EP scenario increases the Korean industrial electricity price to the OECD level until 2030. The ME scenario applies MEPS to three-phase induction motors of $200 \mathrm{~kW}$ or more, for which the standard was assumed to be similar to that of the EU $(95.1 \%$ - the efficiency threshold for IE2 four-pole motors). ${ }^{7}$ The LF scenario improves the motor load factor by as much as $75 \%$, which maximizes motor efficiencies. ${ }^{8}$ The VD scenario installs VSDs on electric motors, and the MX scenario runs all of these options simultaneously. Each scenario is summarized in Table 6.

\footnotetext{
${ }^{6}$ An increase in electricity price may be passed on to consumers by an increase in product prices or absorbed by industry in other ways in the short run. However, in the long run, demand on electricity will decrease due to such increase.

${ }^{7}$ Minimum efficiency standards for motors over $200 \mathrm{~kW}$ in the USA and the EU are 95.4 95.8 and 95.1\%, respectively.

${ }^{8}$ It is not desirable to increase load factor all the time as different load factors can be selected based on the purpose of using motors. However, this study analyzes the possible maximum electricity reduction capacity of motors when properly chosen motors reach the maximum load factor as it focuses on the issue of using oversized motors.
} 
Table 5 Efficiency improvement and cost

\begin{tabular}{llll}
\hline & & $\begin{array}{l}\text { Pumping } \\
\text { system }\end{array}$ & Fan \\
\hline \% Improvement in energy efficiency & Over low efficiency base case & 25 & 35 \\
& Over middle efficiency base case & 15 & 20 \\
& Over high efficiency base case & 10 & 8 \\
Cost (\$) & $\sim 37 \mathrm{~kW}$ & 4000 & 8000 \\
& $37 \sim 75 \mathrm{~kW}$ & 9000 & 15,000 \\
& $75 \sim 150 \mathrm{~kW}$ & 18,000 & 30,000 \\
& $150 \sim 370 \mathrm{~kW}$ & 30,000 & 80,000 \\
& $370 \mathrm{~kW} \sim$ & 65,000 & 150,000 \\
\hline
\end{tabular}

Source: UNIDO (2010)

\section{Results}

The model's projections of electricity consumption in each scenario for 2010-2030 (price elasticity $=0.460$ ) are shown in Fig. 6. Electricity consumption can be reduced from the BAU scenario each year through the EP, LF, or VD scenarios. The EP scenario reduces electricity consumption the most. On the other hand, the ME scenario has a relatively small electricity-saving effect.

Table 7 shows cumulative electricity consumption and cost by scenario. The costs include the initial investment cost, the annual O\&M cost, and the electricity cost. ${ }^{9}$ The lattermost accounts for 94 97 \% of the total cost, as electric motors are energy-intensive and have long lifetimes. Therefore, it is important to reduce electricity consumption more than anything else. Electricity consumption and cost decrease remarkably with an increase in the electricity price (EP, MX), although the extent depends on the price elasticity of demand for electricity. In the case of the EP scenario, the investment cost and annual O\&M cost is relatively small because the demand for motors lowers in the long run as the electricity price goes up. In the case of the VD scenario, the cost is relatively high due to the cost to install VSDs.

Table 8 shows electricity consumption change, cost change, and the unit reduction cost compared to BAU by scenarios, that were calculated on the basis of Table 7 .

Assuming a price elasticity of 0.460 , the EP scenario can reduce electricity usage by $130 \mathrm{TWh}(7.5 \%$ of BAU electricity consumption) by 2030 , which is the largest reduction as a single reduction plan. It also offers the

${ }^{9}$ In this paper, electricity cost is calculated by the electricity price which is expected as the average industrial electricity price of OECD countries in 2030 . We apply the price at EC scenario. largest cost reduction among the scenarios. However, the ME scenario has the lowest electricity reduction, as high-efficiency technologies for large-capacity motors are not developed enough and because the electricity reduction potential is not large. The MX scenario can reduce electricity consumption by as much as $170 \mathrm{TWh}$ ( $9.8 \%$ of BAU electricity consumption) by 2030 .

In terms of unit reduction cost, the LF scenario emerged as the alternative plan with the greatest benefit $(-108.7 \mathrm{KRW} / \mathrm{kWh})$, because improvements in load factors improve motor efficiency without any additional costs. Apart from the ME scenario, the remaining scenarios also showed negative values for their unit reduction costs. This shows that an efficiency improvement can result in a greater benefit than a cost improvement, as the electricity cost accounts for most of the total cost (94 97\%) and because reduced electricity consumption translates into cost savings. This finding reflects discussions in previous studies (e.g., McKinsey and Company 2009) of how industrial efficiency improvements can result in negative costs.

Meanwhile, the ME scenario emerged as the alternative that resulted in the lowest electricity reduction

Table 6 Scenarios

\begin{tabular}{ll}
\hline Scenario & Content \\
\hline BAU & MEPS \\
EP & $\begin{array}{l}\text { Increase of industrial electricity price (same as OECD } \\
\text { average in 2030) }\end{array}$ \\
ME & $\begin{array}{c}\text { Expansion of MEPS (including three-phase induction } \\
\text { motors of } 200 \mathrm{~kW} \text { or more) }\end{array}$ \\
LF & $\begin{array}{c}\text { Enhancement of motor load factor (75 \%) } \\
\text { VD }\end{array}$ \\
MX & $\begin{array}{l}\text { Installation of VSD } \\
\text { Includes all options }\end{array}$ \\
\hline
\end{tabular}


Fig. 6 Projections of motor electricity consumption in manufacturing (price elasticity= $0.460)$. Note: The ref scenario is the result of the assumption that MEPS is not applied

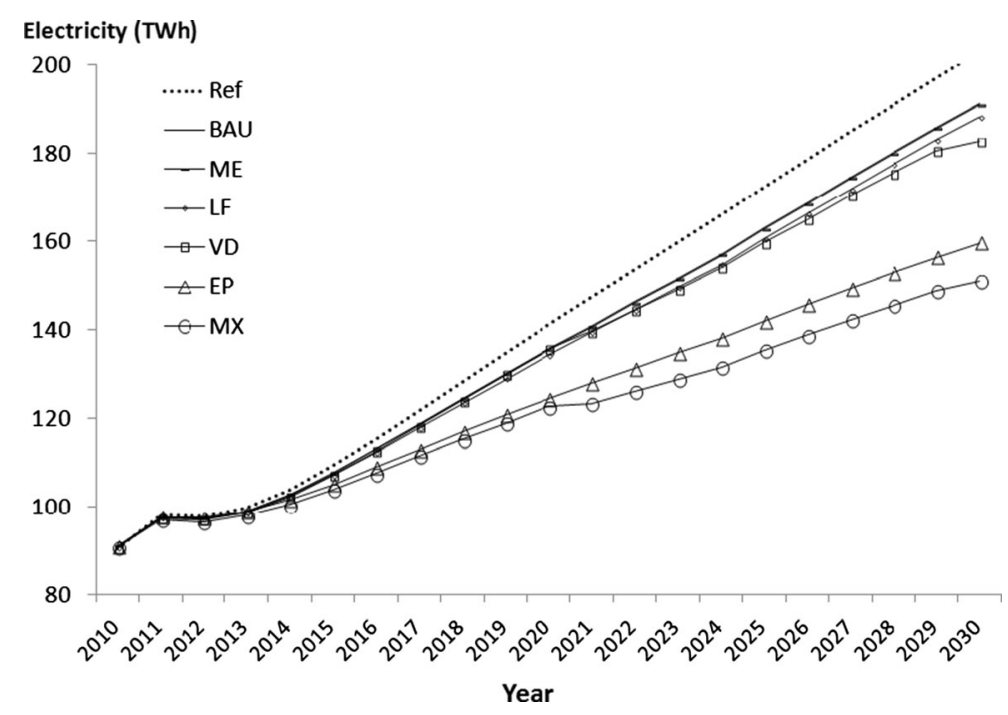

amount and had the most expensive unit reduction cost $(32.7 \mathrm{KRW} / \mathrm{kWh})$. This result was observed because the development of high-efficiency technology is not sufficiently realized and does not have a large electricity reduction potential. However, the unit reduction cost of the ME scenario is lower than the lowest real industrial electricity price for 2010-2030 (66.0 KRW/kWh); hence, the expansion plan of MEPS also appears to have major benefits. If the technical development of largecapacity motors is realized under MEPS in the future, the potential reductions in electricity consumption will be even greater.

Even if other price elasticity values $(0.66$ or 0.045$)$ are used, as a stand-alone plan, the increase in the electricity price showed the greatest effect on energy reduction. Using the other price elasticities did not substantially alter unit reduction costs.

\section{Conclusions}

This study analyzed the economic feasibility and electricity savings potential of different strategies to reduce the energy use of electric motors in Korea. And because electric motors in manufacturing represent one fifth of all electricity consumption in Korea, they are very important in electricity-demand-control efforts, as are the reduction scenarios dealt within this study. Our findings present a number of important policy implications.
Table 7 2010-2030 cumulative electricity consumption and cost of motors in the Korean manufacturing, by scenario

\begin{tabular}{|c|c|c|c|c|c|}
\hline \multirow[t]{2}{*}{ Scenaric } & & \multirow{2}{*}{$\begin{array}{l}\text { Cumulative } \\
\text { electricity (TWh) }\end{array}$} & \multicolumn{3}{|c|}{ Cumulative cost (billion KRW) } \\
\hline & & & $\begin{array}{l}\text { Electricity } \\
\text { cost }\end{array}$ & $\begin{array}{l}\text { Investment cost and } \\
\text { annual O\&M cost }\end{array}$ & Sum \\
\hline \multicolumn{2}{|l|}{ BAU } & 1724 & 135,963 & 5448 & 141,411 \\
\hline \multirow[t]{3}{*}{ EP } & $\mathrm{EP}^{\mathrm{a}}$ & 1544 & 120,937 & 4576 & 125,513 \\
\hline & $\mathrm{EP}^{\mathrm{b}}$ & 1594 & 125,156 & 4850 & 130,007 \\
\hline & $\mathrm{EP}^{\mathrm{c}}$ & 1702 & 134,144 & 5443 & 139,587 \\
\hline \multicolumn{2}{|l|}{ ME } & 1722 & 135,800 & 5676 & 141,475 \\
\hline \multicolumn{2}{|l|}{ LF } & 1708 & 134,651 & 5031 & 139,682 \\
\hline \multicolumn{2}{|l|}{ VD } & 1704 & 134,287 & 6118 & 140,405 \\
\hline \multirow[t]{3}{*}{ MX } & $\mathrm{MX}^{\mathrm{a}}$ & 1506 & 117,816 & 4732 & 122,547 \\
\hline & $\mathrm{MX}^{\mathrm{b}}$ & 1554 & 121,867 & 5014 & 126,881 \\
\hline & $\mathrm{MX}^{\mathrm{c}}$ & 1658 & 130,490 & 5623 & 136,113 \\
\hline
\end{tabular}


Table 8 Electricity consumption change, cost change, and unit reduction cost compared to BAU by scenarios

\begin{tabular}{lllll}
\hline Scenario & & Electricity consumption change $(\mathrm{GWh})$ & Cost change (billion KRW) & $\begin{array}{l}\text { Unit reduction cost } \\
(\mathrm{KRW} / \mathrm{kWh})\end{array}$ \\
\hline $\mathrm{EP}$ & $\mathrm{EP}^{\mathrm{a}}$ & $180(10.5 \%)$ & $-15,899$ & -88.3 \\
& $\mathrm{EP}^{\mathrm{b}}$ & $130(7.5 \%)$ & $-11,405$ & -88.0 \\
& $\mathrm{EP}^{\mathrm{c}}$ & $22(1.3 \%)$ & -1824 & -83.7 \\
$\mathrm{ME}$ & & $2(0.1 \%)$ & 64 & 32.7 \\
$\mathrm{LF}$ & & $16(0.9 \%)$ & -1729 & -108.7 \\
$\mathrm{VD}$ & & $20(1.2 \%)$ & -1006 & -50.1 \\
$\mathrm{MX}$ & $\mathrm{MX}$ & $-18,864$ & -86.5 \\
& $\mathrm{MX}$ & $218(12.6 \%)$ & $-14,530$ & -85.8 \\
& $\mathrm{MX}$ & $170(9.8 \%)$ & -5298 & -80.3 \\
\hline
\end{tabular}

Electricity and cost are discounted to 2010 value. Values in brackets mean ratios of electricity consumption change compared with BAU

${ }^{\text {a }}$ Price elasticity $=0.66$

${ }^{\mathrm{b}}$ Price elasticity $=0.460$

${ }^{\mathrm{c}}$ Price elasticity $=0.045$

First, investments in electricity consumption reductions are connected to remarkable cost savings. More active publicity and investments in motor energy savings should be realized. Active incentives and support for the development of high-efficiency motors and the installation of VSDs are necessary. Specifically, the government's existing high-efficiency VSD support policy should be continued consistently. In addition, the government should enact various consulting and education programs that help motor users overcome the energy efficiency paradox, the phenomenon in which individuals and firms hesitate to invest in profitable energysaving businesses.

Second, an increase in the electricity price is more necessary than any other method to control electricity demand. Korea has implemented various electricitydemand-control policies while maintaining a low electricity price thus far. However, these measures have been ineffective, showing that it is necessary to increase the electricity price. However, increasing the electricity price is politically challenging because the Korean government has kept the industrial electricity price low and the electricity-intensive industrial structure has been maintained thus far. Regardless, an increase in the electricity price is overdue and sorely needed. Improved communications by the government with industry and society about the necessity of increasing electricity prices in relation to the issues of energy security and climate change may help smooth over the inevitable resistance to rate increases.
Third, if properly enforced, a form of MEPS for motors is desirable in that it can reduce electricity consumption remarkably through improvements in the efficiency of electric motors. Although an expansion of MEPS has less potential to reduce electricity use and is relatively expensive compared to other plans, it appears to be feasible because the unit reduction cost is lower than the industrial electricity price. Moreover, the enforcement of MEPS can result in technical developments and efficiency improvements which can reduce electricity consumption even more.

Fourth, it is important for users to select motors of the proper capacity so that their load factors will not be too low. The government should provide information and guides for users to calculate and improve their load factors.

Open Access This article is distributed under the terms of the Creative Commons Attribution License which permits any use, distribution, and reproduction in any medium, provided the original author(s) and the source are credited.

\section{References}

Beggs, C. (2009). Energy efficient electrical services, management, supply and conservation. Energy: management, supply and conservation, 2nd ed, 288-314.

Bortoni, E. D. C. (2009). Are my motors oversized? Energy Conversion and Management, 50, 2282-2287. 
CEE (Consortium for Energy Efficiency). (2011). Motor efficiency, selection and management - a guidebook for industrial efficiency programs.

Cha, K. S., Park, K. S., \& Kim, S. I. (2008). Base building for analysis and projection of energy supply and demand. (in Korean).

DOE (Department of Energy). (2002). the United States industrial electric motor systems market opportunities assessment.

DOE (Department of Energy). (2008). Improving motor and drive system performance - a sourcebook for industry.

Hur, G. H. (2013). Problems and improvement issues of 6th power supply and demand basic plan. National Assembly Budget Office. (in Korean).

IAEA (International Atomic Energy Agency). (2007). MESSAGE user manual.

IEA (International Energy Agency). (2012a). Electricity information 2012 with 2011 data.

IEA (International Energy Agency). (2012b). Spreading the net: the multiple benefits of energy efficiency improvement.

IEA (International Energy Agency). (2012c). World energy outlook 2012.

IEA (International Energy Agency). (2013). 2013 Energy prices and taxes - quarterly statistics - second quarter 2013.

Jeong, H. K. (2011). Current state, causes and solutions of power consumption increase in winter. Conference on sustainable electricity and price policy. (in Korean).

Jeong, H. K., \& Park, K. S. (2010). Total research for establishing market-friendly energy price system. Korea energy economics institute. (in Korean).

Jo, Y. T. (2012). How to respond to the energy electrification. The Korea Petroleum Association Journal, 286, 19-22 (in Korean).

KEMCO (Korea Energy Management Corporation). (2004). Establishment of energy technology database. (in Korean).

KEMCO (Korea Energy Management Corporation). (2009). Common elemental equipments technology data survey for establishment of GHG reduction technology database: focused on industrial, commercial \& household equipments. (in Korean).

Kim, S. D. (2009). An analysis of industrial city gas and power demand with its focus on price system. Journal of Korean Society Mineral and Energy Resources Engineers, 46(3), 1-8 (in Korean).

Mckinsey \& Company. (2009). Pathways to low carbon economy-version 2 of the global GHG abatement cost curve.

Messner, S., \& Strubegger, M. (1995). User's guide for MESS AGE III. IIASA.

MKE (Ministry of Knowledge Economy). (2008). Survey for supply and utilization pattern of electromotive force instrument. (in Korean).

MKE (Ministry of Knowledge Economy). (2012a). 2011 energy consumption survey. (in Korean). www.keei.re.kr/keei/ download/ECS2011_Revised.pdf. Accessed 20 August 2014.
MKE (Ministry of Knowledge Economy). (2012b). White paper on demand side management. (in Korean).

MKE (Ministry of Knowledge Economy). (2013). 6th power supply and demand basic plan. (in Korean). http://www. motie.go.kr/common/download.do?fid=bbs\&bbs_cd_n= $37 \& b b s \_s e q \_n=104486 \&$ file_seq $n=1$. Accessed 20 August 2014.

MKE (Ministry of Knowledge Economy) \& KEEI (Korea Energy Economics Institute). (2012). Yearbook of energy statistics 2012. (in Korean). http://www.keei.re.kr/keei/download/ YES2012.pdf. Accessed 20 August 2014.

Natural Resources Canada. (2003). Technical fact sheet-premium-efficiency motors.

Pachauri, S., \& Spreng, D. (2004). Energy use and energy access in relation to poverty. Economic and Political Weekly, 39(3), 17-23.

Park, K. S. (2011). Issues on energy price system and its direction for improvement. Korean Energy Economics Review, 10(2), 111-142 (in Korean).

Reister, D. B., \& Warren, D. D. J. (1981). Total costs of energy services. Energy, 6(4), 305-315.

Saidur, R. (2010). A review on electrical motors energy use and energy savings. Renewable and Sustainable Energy Reviews, 14(3), 877-898.

Saidur, R., Mekhilef, S., Ali, M. B., Safari, A., \& Mohammed, H. A. (2010). Applications of variable speed drive (VSD) in electrical motors energy savings. Renewable and Sustainable Energy Reviews, 16, 543-550.

Seok, K. H. (2012). Power demand-side management and current status and improvement plan of price system. Policy report on Lee Myung-Bak Government Climate Change Policy Evaluation and Policy Challenges of the Next Administration, Institute of Climate Change Policy under the National Assembly Forum on Climate Change (in Korean).

UNIDO (United Nations Industrial Development Organization). (2010). Motor systems efficiency supply curves. http://www. unido.org/fileadmin/user_media/Services/Energy_and Climate_Change/Energy_Efficiency/CCS/UNIDO $\% 20-\overline{0}$ 20 UN-Energy \%20-\%202010\%20-\%20 Motor \% 20Systems\%20Efficiency\%20Supply\%20Curves\%20(2). pdf. Accessed 20 August 2014.

Yun, B. R. (2009). Trend and supply expansion ways for VSD. Instrumentation Technology, July (in Korean).

Yun, S. J. (2013). How to overcome the energy crisis time. Conference on how to overcome the energy crisis timeseeking solutions in domestic and foreign cases. the National Assembly Members' Office Building, Seoul, Korea, the National Assembly member Yu In-Tae (in Korean). 